\title{
An Eco-translatological Perspective on Shenzhen’s International City Image Construction: Public Signs Translation as an Example*
}

\author{
ZHU Xiao-Xuan \\ Shenzhen Tourism College, Jinan University, Shenzhen, China \\ ZHANG Mu \\ Shenzhen Tourism College, Jinan University, Shenzhen, China \\ YAN Bo-wen \\ Institute for Economic and Social Research, Jinan University, Guangzhou, China
}

\begin{abstract}
After the 26th Universiade, Shenzhen has been striving to build a balanced and harmonious translational eco-environment, and make Public Signs translation play a positive role in the construction of international city image. Meanwhile, Shenzhen has formed relative completed systems in beforehand prevention and subsequent punishment in public signs translation. However, there is also a long way to go to perfect the translation eco-environment construction.
\end{abstract}

Keywords: city image formation, eco translation, public signs translation, ecological construction

\section{Introduction}

Since the Reform and Opening-up policy came into operation 40 years ago, continuous development and construction has transformed Shenzhen,the first special economic zone in China, from a small fishing village into a modern, international metropolis with a population of 20 million. The success of the 26th Universiade in 2011 has marked a noticeable progress in the protection and improvement of urban environment, city infrastructure building, as well as the construction of international language environment and city image. Shenzhen has fully stepped into a new "post-Universiade" era. Aiming at "Building a modern, international, and innovative Shenzhen by 2020" Shenzhen government has seized every opportunity, shaping the city image through diversified and comprehensive ways, among which constructing a global language environment is a priority.

\footnotetext{
*Acknowledgement: This work is funded by National Social Science Foundation of China (Grant No.16AZD055). The project title is: A Study of the Ontology vocabulary of intangible cultural heritage based on Ontology Mapping.

ZHU Xiao-xuan, Ph.D. candidate, teacher in Shenzhen Tourism College, studies on translation theories and literature translation. Email: zhu_xx@sz.jnu.edu.cn.

Zhang Mu, Corresponding author, professor in Shenzhen Tourism College, Jinan University, main research fields are tourism information system, intangible cutural heritage database, and etc.. Email: zhangmu@sz.jnu.edu.cn.

YAN Bowen, undergraduate student, Institution of Economic and Social Research, Jinan University, Guangzhou, Email: 910343913ybw@gmail.com.
} 


\section{City Image Construction and Public Signs Translation}

City image, which belongs to cognitive category, usually refers to human impression and feelings to a city (or a certain area). It is a comprehensive concept which consists of many factors. Generally speaking, there are three main factors in the construction of one's city image, the city's objective existence, the media, and the public's subjective cognitive effects. Three major research procedures are positioning, designing and spreading (Yang, 2013). The concept of city can be traced back to Plato's Republic, but it was not until the industrialization age that people started to design and position cities with consciousness and reason. Nevertheless, industrialization broke the balance and harmony between human beings and the environment, and this was the time when human began to notice the importance of sustainable development. In 1980s, the United Nations World Commission on Environment and Development (WCED) led by Gro Harlem Brundtland raised the concept of Sustainable Development. From then on, the design and research on city images have been focusing on environment, ecosystem, as well as the physical and mental health of mankind.

The study in Chinese city image is originated in the urban beautification concept in 1920s. It was not until 1990s that the city image concept was put forward explicitly. Qian Zhi believed, creating a city image is a process of mutual communication between the city and the public via certain media, which involves many sessions, from messages receiving by the public, processing, action and feedback, to city information encoding, information transferring, and action adjusting (Qian, 2002).

Morgan and Pritchard (2002) compared city image to "cultural currency", which indicates culture can function as currency to exchange for people's needs, such as attracting tourists, business promotion, investment, immigration, and settlement. Constructing an international city image is tied up with the construction of international language environment, in which translation plays a vital role. But if translation does not receive abundant attention as it deserves, this "cultural currency", is bound to depreciate. Public signs translation, as an international name card for one city, is one of the most direct and noticeable way to extend publicity in cross-culture communication, and an important method for the city's promotion and external communication expansion. To further promote the construction of Shenzhen's city image in the "post-Universiade" time, Wu (2012, pp. 67-71) proposed that "reinforcing the urban visual system", that is to say, constructing and translating public signs within the city, should be the main focus. Based on eco-translatology theory, this article aims to study the translation ecology for public signs, as well as its impact on the construction of international language environment, and the process of structuring and disseminating a mature, international city image of Shenzhen.

\section{An Eco-translatological Perspective on Shenzhen's Public Signs Translation}

Dated back to the early 20th century, eco-translatology theory is the first translation theory raised by domestic researchers. It was initialed by Hu Genshen (2001, 2004, 2008, 2011), and was discussed and developed by many other scholars. Later on, the eco-translatology theory caught attention from international theorists and critics, becoming an emerging paradigm of translation research. The theory raises several research focuses, and positioned as "a research paradigm which comprehensively views translation with ecological rational features and ecological perspectives” (Hu, 2013, p. 11). Searching the combined topic "ecological translation” with “public signs” in the China Academic Journal Network Publishing Database, it provides a result of more than 200 relevant literatures. Most of the research targets were taken from public signs translations of 
different cities like Quanzhou, Tianjin, Xi'an, Henan and Wuhan, etc., and more than 90 percent researchers concentrated on the the discussion about the translation quality of public signs based on the principles of "adaptation and selection", "three-dimension transition”. They correct translation mistakes, standardize translation rules, etc. However, many theoretical key points in eco-translatology have not been given enough attention, such as the eco-environment for translation, doing things with translations, and subsequent punishment.

\section{The Eco-environment for Translation}

The eco-environment for translation is the basis of Eco-translatology theory. It refers to "a world consists of the original texts, the source language, and the target language, namely, an entirety wherelanguage, communication, culture, society, along with writers, readers, and assignees interact with each other. The main elements are the source language, original texts and the target language system. It is a unitary environment for the living conditions of the translators and the translation” (Hu, 2004, p. 128). Later, based on further supplement and extension, it is acknowledged that the concept of translation eco-environment should exceed the living condition for translators and translation, to be "the unitary environment where translations take place, with dimensions, levels and more importantly, trans-territorial as its features” (Chen, 2014, pp. 68-73). Researchers classified the eco-environment for translation into different levels of scale, from settlements, regions, nations to the world; and also different dimensions, language, culture, creatures, societies and so forth. Using the analogy of natural environment, Qian Chunhua (2011) and Zhang Yanyan (2014) raised the opinion that the translation eco-environment can be divided into macro-environment and micro-enviroment factors, also called supportive environment factors. Macro-environment factors consist of four aspects, political environment economic environment, social culture and natural environment; while the supportive environment is made up of translation resources, industrial environment, translation researches, and authority factors (Zhang, 2014, pp. 51-54). Take Shenzhen as a regional research object, we can analyse its constitution and characters of the "translation eco-environment" from the perspective of macro and supportive environment.

Considering its macro-environment, Shenzhen is located at the east bank pf Pearl River Delta, with a short history of 40 years, whose city construction development keeps pace of China's Reform and Opening-up Policy. Adhering to Hong Kong, Shenzhen has the largest number of the entry and exit ports along its administrative boundaries and is an important three-dimensional transportation hub in China. As the first economic special zone, Shenzhen plays an increasingly important role in China's economic development. According to the rankings of the city's economic aggregate, Shenzhen ranks as the fourth biggest city in China, following Beijing, Shanghai, and Guangzhou. The economic environment of high-speed development attracts a large number of immigrants from home and abroad, creating a diverse and inclusive immigrate culture. Data revealed by Shenzhen Commercial Daily showed, in 2015, the population of temporary foreign residents was 1,152,000, increased by $17.4 \%$ compared with 2014 . Increased by $7.2 \%$ over 2014 , there were 26,579 permanent foreign residents, who came from 127 countries (regions), and the top 5 countries with the largest number of the foreign residents are Japan, South Korea, the United States, India and Canada. Its unique regional advantage and social environment grant the openness, inclusiveness, and innovation to the city, and made it "a vigorous capital offering the best environment for excellent entrepreneurs global”. Shenzhen was rated by Forbes China as the most innovative city in Chinese mainland. After the 26th Universiade in 2011, Irina Bokova, the former Director-General of the 
United Nations Educational, Scientific and Cultural Organization (UNESCO) praised, "Shenzhen is an unforgettable, energetic city with prosperous vitality, representing the spirit of sustainable development”. Innovation, entrepreneurship and sustainable development have become the keywords of the society development and city image construction in Shenzhen.

Macro eco-environment (political, economic, cultural and social factors) determined the supportive environment in regional translation ecology. Diverse population constitution decides the main language, Mandarin, not Cantonese, which is different from that of other cities and regions in Guangdong province. At the meantime, the continuously growing number of international immigrants and visitors made many public service facilities, professionals and the industrial and commercial circle in Shenzhen offer their service in English. Moreover, most teenagers can speak English. From the time preparing for the Universiade, Shenzhen government and relevant departments had started working on the construction of international language environment in an organized and purposeful way, gaining significant achievements in the foreign language popularization in public service, and citizens' foreign language application.

To analyze the supportive environment of Shenzhen from the perspective of translation resources and industrial environment, we can see many a international political-economic action contain great demand for translation, also breed lots of translation companies and corresponding institutions. Apart from full-time and freelance translators, and translation teams, there are more than 200 translation companies in Shenzhen (Fan, 2009), and the number was expected to have been increasing exponentially starting from 2010 according to the statistics in 2009. On the other hand, Translators Association of Shenzhen was founded in 2005 under the supervision of the Foreign Affairs and Overseas Chinese Affairs Office in Shenzhen municipal government. It consists of Comprehensive Service Department, Membership Service Department, Training Department and Translation Service Department. There are 37 group members, and over 300 individual members. The association also has an expert panel formed by professional foreign language experts from home and abroad, which take charge of assessment and supervision of translation quality, as well as giving advice to the relevant work by governments and the association. International Federation of Translators held its first executive committee meeting in Shenzhen in 2009. Its former chairman, Marion Bowers said, hosting the meeting in Shenzhen showed the increasingly important status of the translation industry in the city. In 2018, to support the “One Belt, One Road (OBOR)” international city development project in Shenzhen, and to cultivate international talents with Shenzhen features, Translators Association of Shenzhen cooperates with Hong Kong Translation Society built a Shenzhen-Hong Kong communication platform together for language industry, promoting the language internalization process in Shenzhen.

Moreover, regular translation competitions and academic activities were held by the government and the industry, which also play an important role in promoting translation atmosphere. Since 2010, the municipal Party committee and government in Shenzhen decided to initiate the international language environment construction projects, which took "Shenzhen citizens speak foreign languages" activity as a key point. They established its organization committee, charged by the deputy mayor who is assigned for foreign affairs. The committee office was set under the city foreign affairs office. It had 35 group members, and had published its work reports on "Shenzhen citizens speak foreign languages" activity on an irregular basis. The committee's work includes organizing speech contests, correcting public signs translations in major administrative districts and in public 
transportation, tourist attractions, compiling series handbooks for Shenzhen citizens, organizing campaigns like public service providers concerning foreign affairs (e.g. taxi companies, prosecutors, tourism corporations) to learn foreign languages. It had made great achievements in comprehensively building an international language environment in Shenzhen, and constructing an international city image, making profound social impact. Another important activity is "Shenzhen translation promotion ambassador competition" which started in 2006. Its influence has been globallynoticeable - there has been more than 1,000 contestants, among whom are many excellent and potential translators, ready to make their contributions to Shenzhen's opening and the economic construction. Also, enthusiasm for translation has been aroused among primary-school, middle-school, universities students and other citizens, thus, a good supportive eco-environment for translation has been established in Shenzhen.

Viewed from the perspectives of macro and supportive eco-environment factors for translation of Shenzhen, an emerging immigrant city, the ecology of both the origin and translation context had been interacting actively, trying to create a win-win situation where they can keep dynamic balance and harmoniously co-exist. Therefore, this situation can positively support the public signs translation from aspects like politic, economic, social, cultural, industrial resources, and administration.

\section{Doing Things With Translations}

In eco-translatology, the concept of "doing things with translation" usually covers these two aspects, translators and translation texts, involving translation motivation of the former, and the objective function of the latter which occupies one of the main discussion points here. There are two mainstream academic opinions towards the research of the function of public signs translation. One is the perspective of applicable function-pubic signs translation has the function of instruction, indication, restriction and enforcement. The other one is the perspective of communicative function based on Les theory of text typology-public signs translation functions as messages, emotion expression and an appealing medium.

Nevertheless, the translation process of public signs highlighted the core of "translation as adaptation and selection”, the fundamental research in eco-translatology. It means, for public signs translators, adaptation and selection are inseparable. Only when the translators successfully adapt to the unique translational eco-environment of Shenzhen city that can they choose the translation texts as the constructors in itstranslational eco-environment. In its translational eco-environment, good translations not only act as instructors, indicators, and communication tools, but also an important part in Shenzhen's urban culture which has profound influence in keeping the balance between the ecology of original texts and translated texts, and the construction of a good international city image for Shenzhen. Professor Hu Genshen raised a critical point when discussing the "doing things"part in "doing things with translation”-“doing things” means to build a national image. External promotion and translation are a country's concrete embodiments of its foreign communication level and social environment construction (Hu, 2013, p. 258).

From the perspective of the translation ecology theory, "doing things"with public signs translation can be separated into two parts. First, "doing things"to construct the ecology of translation language, a "world" presented by the translated texts. It includes the ecology of language, communication, culture, society, and so on. The linguistic characters and social functions of public signs determine the translated texts' functions first focus 
on constructing translation language ecology. Qualified public signs translation should follow the readers' customary language patterns, take the harmonious relations among various cultural elements in the translation texts into consideration. Only in this way can the translated texts'communication intention will interact with its behavior, make the translated texts "sustainable”, and ultimately, build up a harmonious ecology for translation language. Second, “doing things” to counteract on the ecology for original language, promoting the construction and improvement of the whole social ecology. The ecological rationality in eco-translatology lays emphasis on entirety, connection, and dynamic balance. At the time when good public signs translations construct a harmonious ecology for translation language, it's bound to counteract to the "world" built by the original language. Also, it endeavors to sustain the internal harmony within the ecology for original language, and continuously reconcile or restructure the ecology for translation language and the original one so that the balance can be kept. These two inseparable parts in the whole eco-system together promote the construction and improvement of one city's overall language and culture ecology, through their inner connection and on-going active interactions.

Shenzhen's international language environment and city image construction and improvement are illustrated by the "doing things” segment of public signs translation. Early in 2010, Li Yixian, Singapore's ministry of trade and industry and senior minister of state development, was invited to give some advice on Shenzhen's international city construction during his visit in Shenzhen. In the light of Singaporean bilingual environment and city image construction experience, Minister Li made following suggestion- "to improve Shenzhen citizens' general foreign language ability, and construct an international language environment in Shenzhen”. From then on, “’'Shenzhen citizens speak foreign languages”, correcting English public signs and many other activities were held. In 2014, Minister Li visited Shenzhen again. This time, he spoke highly of the achievements Shenzhen made in international language environment construction, for the new look when seeing the English public signs appeared in the airport, hotels, and government office building. He said Shenzhen's internationalization promotion work, and international language environment construction achievements had effectively promoted the development of high-end service industry. With an international language environment and bilingual professions equipped with international finance, trade, and juristic knowledge, as well as other English-speakers human resource in service industry, Shenzhen has gain a development advantage that hardly any other Chinese city can compete (Sun, 2014).

An "airport public signs satisfaction survey" made by WJX.cn includes 184 people with air travel experience. They had respectively been to Beijing Capital International Airport, Tianjin Binhai International Airport, Shanghai Hongqiao International Airport, Hangzhou Xiaoshan International Airport, Guangzhou Baiyun International Airport, Shenzhen Bao'an International Airport and other airports. The survey had questions like, "What do you think of the English translation of public signs by ** airport?", "Have you found any errors in translation of public signs at ** airport?”, etc. The result shows that among 18 interviewees who had been to Shenzhen Bao'an International Airport, 33.33\% thought the airport did great in public signs translationin English, only one said he once found mistakes in English public signs translation. The satisfaction rate ranked the third after 44.71\% for Beijing Capital International Airport, and 34.78\% for Guangzhou Baiyun International Airport. As a window of big city like Shenzhen, the international language environment construction of Bao'an international airportdirectly counteract on the ecology of original language, promoting the process of building 
Shenzhen's city image as an international metropolitan.

\section{Beforehand Prevention and Subsequent Punishment}

In translation ecology theory, the "beforehand prevention" and "subsequent punishment" mechanism respectively refers to the translation requirements and guidelines before translation-the prevention, restriction and standardization of the translators' excessive freedom, and the evaluation and disposal of the translated texts after translation. Professor Hu Genshen once said, since translation is as adaptation and selection, the restriction mechanism for translators lay stress on "subsequent punishment", not "beforehand prevention". But for public signs translation, the characters of original texts, and the social function of translated texts determine that the translation process is not a personalized or private selection, but one which should use series of methods in order to adapt to the city's culture and city image establishment. In public signs translation, it is important for the administrative departments, translation service providers, and information transmission institutions, to formulate and promulgate systematic laws, standards ("beforehand prevention”), establish quality supervision mechanism ("subsequent punishment”). These measures will make a profound and sustainable influence on the construction of an international city image.

Shenzhen government took the Universiade in 2011 as an opportunity, formulated English translation rules and implementation guideline for bilingual signs in public places in shenzhen. The guideline was co-compiled by Foreign affairs office of shenzhen municipal government and Translators Association of Shenzhen, based on the public sighs translation guidebooks in Shanghai, Hong Kong, UK, New York city and so on. Besides, they had many reference materials like, Basic rules of the Chinese phonetic alphabets, Gazetteer Regulations, Shenzhen City Map, and Name of Chinese Government Institution compiled by the editorial department of the Xinhua News Agency. The guideline was categorized into 13 volumes, such as “Traffic Road”, “Organization, Job Title”, "Health Care and Sanitation”, "Tourist Attractions”, etc. The guideline offers relative complete "beforehand prevention” standards and reference materials to public signs translation in Shenzhen. In September 2013, Shenzhen government formulated Regulations for Translation and Usage of English Public Signs in Shenzhen (hereinafter referred to as Regulations). It has been China's first governmentnormative regulations about translation and usage of a city's English public signs. It promotes public signs translation legislation, unifies and improves national standards for public signs translation. Thus, it helps establish a beforehand prevention mechanism in translators' adaptation/ selection process, lays a solid foundation for Shenzhen's international language environment construction, and finally the establishment of an international city image in Post-Universiade time.

On the other hand, early in 2005, Translators Association of China advocated a nationwide campaign called “improve cities' public signs translation”, in which Shenzhen participated as one of the first batch of pilot cities. The website of Translators Association of Shenzhen opened a "Public Signs Translation" column with three sections, “What's new?", “Experts Discussion”, and "Let's Talk”. The column focused on the discussion about Shenzhen's public signs translation situation for streets, map, traffic networks, scenic spots and sanitation industry, and offered some discussions and corrections of the expressions, cultural transmission and communication intention in translation. Apart from that, the Association published "Bulletin on the Regulations of Bilingual Signs in Public Places (Vol. 16)”, and Shenzhen Public Signs Dictionary in 2011, providing 
reference for public signs diffusion institutions. In 2013, the government and Shenzhen Press co-organized “Action E: civic correction of English Public Signs”. During the campaign, citizens rectified 2,378 incorrect English signboards on main roads, and nearly 9,000 bus station English names. More than 5,000 bilingual signs on bus stops were set, and bilingual audio station notification in main bus routes come into real. Meanwhile, the website of Shenzhen Foreign Affairs Office also set a special section for "Shenzhen citizens speak foreign language” project, with "public signs correction” being its important column. This section mainly covered the supervision and investigation of English public signs in administrative regions and professional fields. In accordance with the term in Regulations, "Shenzhen Foreign Affairs Office organised an expert committee specializing in the assessment of English public signs translation. Since then, using newly-translated English public signs must be approved by the expert committee through specified procedures”ㄹ. Take a news report published on the website of the Shenzhen Foreign Affairs Office in 2016 as an example.

English public signs correcting action in 2016 starts now! With the organization of Shenzhen Foreign Affairs Office, experts from home and abroad, correspondents from various media and many others formed a supervision group started their inspection at Xianhu Botanical Garden and Wutong Mountain Forest Park yesterday. They will examine the bilingual public signs in 25 parks all around the city and the correction work will be finished by this September.

The report specified the structure of "subsequent punishment" mechanism—expert committee organize experts and relevant staff members to make irregular inspections on public signs translation in certain areas, such as airport, wharves, public transports, and tourist attractions. The supervision group will give inspection reports, and set deadlines for correction. From then on, a preliminary "subsequent punishment" mechanism was set. It has a three-dimensional structure, with Shenzhen government as its promoter, translation experts as its guidance, and Shenzhen citizens as its major participants.

\section{The Ecological Balance in Public Signs' Translation and the Construction of International City Image}

Based on its innate geographical advantage and social environment, together with its continuous exploration and development, Shenzhen has gradually built a harmonious and balanced eco-environment for translation, in which eco-elements like public signs, translators, translations, target readers, the government, and administrative departments can co-exist harmoniously. This effort has excessivelyaccelerated the construction of international language environment and city image in Shenzhen. However, when it comes to the mechanical promotion of public signs translation to the process of shaping an international city image, and the construction and improvement of the overall translation ecosystem, there still has a long way to go for Shenzhen city.

The eco-system for translation consists of original translation eco-system, management eco-system, market eco-system, educational eco-system, eco-environment relying system and other subsystems. The ecological rationality for translation requires the entirety/connection and dynamic/balanced between different subsystems to be highlighted, interpreting the aesthetics about translation,caring about "translation participants", revealing "translation ethics”, and advocating diversity and unity. To construct and perfect translation ecological system, it is inevitable to involve the entire connection and progressive interaction between these groups of

\footnotetext{
${ }^{1}$ See more regulations on: http://govinfo.nlc.gov.cn/gdsszfz/zfgb/245539a/201310/t20131021_4078051.shtml?classid=401.
} 
subsystems—management ecology and market ecology, market ecology and educational ecology, educational ecology and ontic ecology, which is also the pursuit for public signs translation from eco-translatological perspective.

From the perspective of management eco-system for translation, it involves administrative departments, relevant legislation, rules and regulations, translation quality assessment and evaluation. Shenzhen has issued Regulations to standardize public signs translation and usage, which is a benchmark for translation administration. But the first and foremost important question facing now is that how to ensure the enforcement of the regulation, the punishment of lawbreakers, and how to establish a long-term mechanism to standardize public signs translations, making the Regulationsnot only be read on paper but also realistically enacted during the construction of city image.

Moreover, aimed to reinforce the construction of Chinese professional translator teams, to scientifically, objectively, fairly evaluate the translators' capacity, and to improve Chines translation ecology system, the National Ministry of Personnel has made Translation Professional Qualification (Level) Examination Interim Provisions, and China International Publishing Group has been organized and managed China Accreditation Test for translators and interpreters. This examination is an important method for the identification and education for professional translators, as well as a crucial segment in the chain of translation ecology. Earlier in 2003, the first approved cities, Beijing, Shanghai, Guangzhou, organized the exam. In the first half in 2004, the interpretation exam spots expanded to 6 cities, the translation to the number of 12 cities. In the second half, the interpretation exam spots expanded to 25 cities, the translation to 15 . But after more than 10 years, there's still no exam spot or course professors or systematic training programs initiated by universities or education institutes in Shenzhen, a city with extremely high demand for translation and increasingly improved eco-environment for translation. It not only fails to meet the economic and social development demand of China's first-tier city, but also fails to investigate the translation participants from eco-translatological perspective. It's a showcase for the eco-environment defect in translation education, and it's incompatible with the Shenzhen's city image as an international metropolitan.

In the end, the ontic translation eco-system is the core of the whole translation eco-system, as well as the highest point for the research's progressive process. With the characteristics of being rational and logical, it's worth researching and discussing. Different schools and genres around the system are an important mark of its vitality and dynamic. There are no specialized translation majors, research subject and columns in the universities, academic institutes, and journals, which can neither support the construction of eco-system for translation theoretically, nor guide the translators to take their responsibility and improve translation quality practically. Fortunately, the social science institute in Chinese University of Hong Kong (Shenzhen) first designed an under-graduate program for Chinese-English translation, translation and interpretation, and a master program for simultaneous interpretation in 2006. It marked a good start of the construction of the ontic translation eco-system in Shenzhen, but Shenzhen should spend many years and great effort to establish a real complete and balanced original translation eco-system.

Considering the above problem, in order to construct and improve the eco-system for translation, to reinforce the construction of international language environment and to build an international city image, these following measures would be helpful: 
(1) To educate and train professional translators, make them take the responsibilities, and improve translation quality. Among the translation participants, translators are responsible for reconciling interest relations, adapting to eco-environment, cultivating the ecology for translation, and receiving and diffusing the translated works, so as to reach the goal of "doing things with translation”. In terms of public signs translation, the Regulations and Guidance should be popularized among the translators' group. Translators in relevant government department, public institutions and the translation office in corporations should be organized to take systematic course, define the translators' responsibilities and obligations, and familiarize themselves with the public signs translation provisions and relevant regulations in Shenzhen. At the same time, the corresponding vocational examination and recruitment should add the Regulations and Guidance into the exam content. Therefore, more potential translators can proactively learn relevant knowledge and rules so that they can play an active role in practical translation process, providing marketable products and reaching the trans-cultural communication goal among the consumers. The pre-examination mechanism of English public signs should be enacted, with which translation examination be strictly checked. Therefore, the translators' performance will be closely linked to translation quality, and this will help the translators to proactively undertake their responsibilities and improve their translation ability. It's recommended that translation expert be irregularly organized to examine categorized English public signs. For ordinary citizens, they can also be encouraged to correct the English public signs in the city, and some typical translation mistakes and correction results should be published on a regular base like on newspaper, websites, TV news, and other media platforms. To improve translation quality, all kinds of support from governmental policies, regulations, practical mechanism, public supervision and many other areas are also needed.

(2) To organize diverse translation activities, enhance academic research. To better improve the theoretical level of translation, and apply translation theories to translation practice, metaphysically instruct the cause of international city image building, Shenzhen government and relevant departments can cooperate with universities, institutes, journals and Translators Association of Shenzhen, hold diverse industrial and academic activities to support the development of original translation eco-system. For example, take its unique geographical advantage, Shenzhen can build an academic communication platform, organize academic forum for translation with Hong Kong and Macao, which have internationally acknowledged translation theoretical achievements and excellent practical performance and will help toobtain unique and beneficial experiencesin international language environment construction. Secondly, local universities should be encouraged to establish research institutes, and journals should set up columns for theoretical discussion about public signs translation. Cooperation with other domestic cities is also a good solution. These promotion measures of formulating and popularizing national standards and relevant regulations about public signs translation will play a positive role in constructing an international city image.

\section{Conclusion}

After years of vigorous construction and improvement, the construction of the ecological translation for public signs in Shenzhen has gained steady progress and accomplishment. For relevant work, foreign experts commented on the achievements that, "most of Shenzhen's public signs are expressed in authentic English, despite some 'Chinglish' and inconsistency problems appearing in some descriptive expressions of technical 
terms”. The standardization and improvement of public signs translation represents periodical achievements of constructing an international city image in Shenzhen. Eco-elements like government departments, writers, translators, readers and promoting mechanism etc. have constituted a harmonious coexisting community, which starts to develop in a balanced and steady way.

However, as Professor Tao (2017) stated, “currently, Shenzhen’s internalization is out of sync with its opening-up process, with innovation being its lifeblood, the key to Shenzhen’s future development is to build a complete legislation system on international talent introduction”. The construction of international language environment is bound to offer the most significant social-environment support to the buildingof an international city imageand a mechanism for international talents introduction in Shenzhen, and that also shows us the direction towards which the Shenzhen's ecological construction of translation should advance.

\section{References}

Anholt, S. (2002). Destination branding: Creating the unique destination proposition. N. Morgan, A. Pritchard and R. Pride, (Eds.). Oxford, UK: Butterworth Heinemann.

Chen, S. P. (2014). The paradox of eco-translatology. An discussion with professor Hu Genshen. Chinese Translators Journal, (2), 68-73.

Fan, J. G. (2009, April 25). "Shenzhen urgently needs high level translation talents”, municipal leaders commented when meeting executive members of International Federation of Translation. Shenzhen Special Zone Daily, A03.

Hu, G. S. (2013). Eco-translatology: Construction and interpretation. Beijing: The commercial Press.

Hu, G. S. (2004). An approach to translation as adaption and selection. Wuhan: Hubei Education Press.

Kerridge, R. (1998). Introduction. In R. Kerridge and N. Sammells (Eds.), Writing the environment:ecocriticism and literature. London: Zed Books.

Qian, Z. (2002). City image design. He Fei: Anhui Education Press.

Sun, J. (2014, September 14). An interview of senior minister of Singapore commercial industry and country development ministry: To broaden "marine silk way” by collaboration of Shenzhen and Singapore. Shenzhen Special Zone Daily, A02.

Tao, Y. T. (2017, February 21). The standard of internationalization determines how far Shenzhen can go in modern development [DB/OL]. http://www.sohu.com/a/126827850_114731

Wu, J. Z. (2012). The cultural effects of the universiade and Shenzhen's urban image. Journal of Shenzhen University (Humanities \& Social Sciences), (1), 67-71.

Yang, X. M. (2013). City image research: Methodology, theory and trends. Journal of Southwest Minzu University (Humanities and Social Science), 3, 68-71.

Zhang, Y. Y. (2014). The macro eco-environment of public signs translation. Journal of Chinese Language, (10), 51-54. 